\title{
Vírus Linfotrópico de células T Humana (HTLV): doenças associadas e dificuldades no diagnóstico e tratamento.
}

\author{
Human T-lymphotropic virus (HTLV): associated diseases and difficulties in \\ diagnosis and treatment.
}

Wellison Amorim Pereira ${ }^{1}$, Ericka Miranda Mesquita ${ }^{2}$.

E-mail: wellison.amorim@hotmail.com

\begin{abstract}
Resumo: Os vírus linfotrópicos de célula T humana (HTLV tipo I e tipo II) são retrovírus morfologicamente parecidos que estão associados a quadros clínicos e doenças diferentes. $O$ HTLV não tem cura, é assintomático, seu diagnóstico dificilmente é feito antes do aparecimento das doenças a que o vírus está associado, e estas normalmente levam à incapacitação física do indivíduo, depressão e morte. O Brasil possui o maior número de infectados, mas não dispõe de programas efetivos de contenção da transmissão do vírus. Poucos estudos profundos envolvendo o tema são feitos, e este fato colabora para o ineficiente retardamento do avanço das degenerações HTLV associadas. As manifestações clínicas só pioram com o tempo, e o indivíduo se vê perdendo suas funções físicas, enfrentando uma doença desconhecida e tomando remédios que, no máximo, retardarão sua morte. A falta de informação, até por parte dos profissionais da área da saúde, dificulta sua terapêutica. $O$ presente estudo foi feito com base na análise e extração de informações coletados a partir de periódicos científicos atuais. Foram atualizadas as informações acerca da patogenia, precariedade do diagnóstico e tratamento de doenças associadas ao HTLV no Brasil e dados epidemiológicos que comprovam a endemicidade do vírus no país.
\end{abstract}

Palavras-chaves: HTLV. Infecções por HTLV-I. Epidemiologia do HTLV. HTLV no Brasil.

Abstract: Human T-lymphotropic virus (HTLV type I and type II) are morphologically similar retroviruses that are associated with different clinical conditions and diseases. The HTLV has no cure, is asymptomatic, your diagnosis is rarely made before the onset of diseases to which the virus is associated, and these usually take the individual physical disability, depression and death. Brazil has the largest number of infected but has no effective containment of transmission of the virus programs. Few deep studies of the subject are made, and this fact contributes to the inefficient delaying the advancement of HTLV associated degeneration. Clinical manifestations only get worse with time and the individual finds himself losing their physical functions, facing an unknown disease and taking medication that, at best, slow down his death. The lack of information, even on the part of health professionals, hinders their therapy. This study was based on the analysis and extraction of information collected from current journals. The information was updated on the pathogenesis, precariousness of diagnosis and treatment of diseases associated with HTLV in Brazil and epidemiological data that prove the endemicity of the virus in the country.

Key-words: HTLV. HTLV-I Infections. Epidemiology of HTLV. HTLV in Brazil

\footnotetext{
${ }^{1}$ Graduados do Curso de Biomedicina - UNICEUMA

${ }^{2}$ Docentes da Universidade Ceuma
} 


\section{Introdução}

Os vírus linfotrópicos de célula T humana, do inglês Human $T$ Lymphotrophic Viruses (HTLV), são retrovírus, subdivididos em tipo I (HTLV-I) e tipo II (HTLV-II) ${ }^{29}$. São classificados como pertencentes à família Retroviridae, subfamília Orthoretrovirinae e gênero Deltaretrovirus ${ }^{17}$.

Sua morfologia é esférica e tem diâmetro de aproximadamente 80 a 100 nanômetros. Cada partícula viral é revestida por envelope de natureza lipoproteica, advindas da célula que fora parasitada. As proteínas que compõe a superfície viral estão arranjadas de forma icosaédrica, formadas pelas proteínas estruturais p15, p19 e p24. Seu material genético é do tipo RNA de fita simples,e este posteriormente será transcrito em DNA de fita dupla ${ }^{25}$.

Possui os genes estruturais env (envelope viral), pol (polimerase) e gag (grupo antigênico) e região $p X$ (que apresenta genes que codificam proteínas que estão ligadas a patogênese viral: Tax, Rex, HBZ, $P 12, P 13, P 30$ e $P 21)$ margeado por sequências terminais repetitivas (LTR - long terminal repeats) ${ }^{11}$.

Tax e Rex (as quais os genes responsáveis por sua codificação estão presentes na extremidade 3' do material genético do vírus)são proteínas que são responsáveis por regular o funcionamento do HTLV. A proteína Tax atua na intermediação dos processos que envolvem a transcrição viral, levando a imortalização dos linfócitos $T$ e posterior surgimento de patologias associadas ao vírus, como o linfoma/leucemia de células $\mathrm{T}$ do adulto (ATLL) e a paraparesia espástica tropical (TSP/HAM). A proteína $R e x$, por sua vez, atua na regulação do processo póstraducional do genoma viral, o processamento do RNAm ${ }^{12}$.

O HTLV divide-se em HTLV tipo I (HTLV-I) e o tipo II (HTLV-I). Esta classificação é importante por que, mesmo sendo semelhantes, ambos possuem forma de atuação distinta e estão associados a patologias diferentes. O HTLV-I ocasiona complicações graves no organismo, enquanto o HTLV-II não está frequentemente associado a nenhuma patologia ou desarranjo na homeostasia corporal ${ }^{20}$.

Os linfócitos T CD4+ e T CD8+ são hospedeiros preferenciais do HTLV I e II, porém, o linfócito $T$ CD4+ é o hospedeiro primário do HTLV-I ${ }^{16}$.

O HTLV possui tropismo por linfócitos $\mathrm{T}^{14}$. A fixação do vírus à membrana da célula hospedeira é o ponto de partida da infecção. Para isto 0 vírus passa a produzir, utilizando a maquinaria da célula, proteínas do futuro envelope viral, que irão facilitar o processo de interação patógeno-hospedeiro da nova partícula viral ${ }^{7}$.

A glicoproteína gp41 é responsável pela fixação na célula hospedeira, e a glicoproteína gp21 pela penetração do respectivo vírus. Após a entrada do HTLV no linfócito $\mathrm{T}$, este se replica através das enzimas transcriptase reversa, protease e integrasse. As novas partículas virais saem por brotamento e passam a infectar novas células, dando início a um novo ciclo ${ }^{24}$.

Suas principais formas de transmissão são por via sexual, hematológica e vertical (TV) ${ }^{27}$. Em 
países onde são observadas altas taxas de prevalência da doença, como no Brasil, por exemplo, a transmissão vertical é protagonista na cadeia de transmissão, principalmente por aleitamento materno ${ }^{4}$.

A principal característica da infecção por HTLV é a sua perenidade. Na maioria dos casos o vírus desenvolve-se de forma a não prejudicar o infectado e, por isso, perdura de forma assintomática e indetectável pelo sistema imune por anos, décadas e, em alguns casos, por toda a vida do hospedeiro ${ }^{6}$.

O HTLV-I pode induzir eventos que levam a polarização celular e formação de uma estrutura proteica que permitirá a sua interação e disseminação via célula-célula, infectando células sadias, pelo processo chamado de sinapse viral 11

Estudos de investigação da patogenicidade do HTLV revelaram sua associação com diversas doenças inflamatórias e degenerativas ${ }^{2}$. As alterações na resposta imune, em decorrência da infecção pelo vírus HTLV-I, aumentam consideravelmente 0 risco de contrair doenças infecciosas, como a estrongiloidíase (infecção causada por verminose) e tuberculose (infecção causada por bactéria), por exemplo ${ }^{10}$.

Martins et al. ${ }^{13}$ afirmam que "dos infectados pelo vírus, cerca de 5 a $10 \%$ poderão desenvolver doenças incuráveis". Segundo Proietti et al. ${ }^{21}$ :

"Células $\mathrm{T}$ infectadas pelo HTLV possuem uma maior capacidade de deslocamento para o interior do sistema nervoso central, liberando citocinas e outras substâncias neurotóxicas lesivas, ocasionando perda ou disfunção celular".

Por induzir o corpo a produzir altas taxas de $\mathrm{MHC}$, antígenos na sinóvia e citocinas pró-inflamatórias, comprova-se a relação intrínseca do HTLV-I com o desenvolvimento de autoimunidade e artropatia ${ }^{26,22}$. As doenças relacionadas ao HTLV mais prevalentes são:

Paraparesia espástica tropical Mielopatia associada ao HTLV-I (TSP/HAM): estima-se que 2 a $3 \%$ dos indivíduos infectados pelo HTLV-I irão desenvolver TSP/HAM 16. É uma doença neurológica, inflamatória, progressiva e de caráter crônico. Sua incidência varia em diferentes regiões do mundo, com baixos índices de acometimento em moradores do Japão e ilhas do Caribe e maior índice no Brasil, especialmente no estado de Minas Gerais ${ }^{15,28}$.

O período de incubação do HTLV-I é longo e, por esta razão, a sintomática é inexistente. A proteína Tax age como facilitadora da passagem das células $\mathrm{T}$ CD4+ infectadas, causando a póstuma infecção do sistema nervoso central. Os neurônios passam a ter contínua perda da mielina (substância que envolve o axônio neural, permitindo que o impulso gerado no corpo dos neurônios se propague e alcance, com maior velocidade, a região que irá estimular). Fisiopatologicamente, observa-se preponderantemente paraparesia espástica progressiva, distúrbio esfincteriano (com perda sensorial ou não), distúrbio intestinal, disfunção motora (fraqueza dos membros inferiores) e disfunção erétil ${ }^{12}$.

Leucemia/linfoma de célula $T$ do adulto (ATLL): a ATLL predomina no sexo feminino numa razão de 
1,4:1. Foi inicialmente descrita no Japão em 1977. É uma doença agressiva, linfoproliferativa, causada por linfócitos $T$ maduros ${ }^{24}$. Baseado nos achados clínicos e na morfologia celular, a ATLL é classificada em quatro tipos: ATLL latente (desenvolvimento demorado, maior tempo de sobrevida), ATLL crônica (agressiva, pouco tempo de sobrevida), ATLL linfoma e ATLL aguda $^{23}$.

O quadro sintomatológico clássico inclui: mal-estar, febre, linfadenopatia, hepatoesplenomegalia, perda de peso, lesões cutâneas, icterícia, sede, fadiga e imunossupressão. Alterações na morfologia nuclear das células $T$ (que se mostram com núcleo multilobulado) são observadas ${ }^{12}$.

Artrite Reumatóide $(A R)$ : doença inflamatória sistêmica, de caráter crônico e progressivo, de natureza autoimune, que lesa a membrana sinovial, em alguns casos ocasionando destruição dos ossos e cartilagens. Estudos demonstram que o HTLV-I é um agente capaz de desencadear e perpetuar doenças inflamatórias crônicas, pois os linfócitos parasitados pelo vírus produzem uma maior quantidade de citocinas pró-inflamatórias, que agem estimulando a proliferação das células sinoviais ${ }^{18}$.

O período de incubação do HTLV é longo e não se está completamente elucidada a forma como o vírus age no intuito de conter ataques do sistema imunológico e permanecendo assintomático por um longo intervalo de tempo. Pouco menos se sabe sobre qual fator acionaria 0 gatilho para 0 início do desenvolvimento das doenças a que o HTLV está associado ${ }^{25}$.

A teoria mais aceita para a origem do HTLV no continente Americano diz que este foi trazido na era paleolítica por imigrantes que atravessaram o estreito de Bering e, posteriormente, por escravos advindos de países africanos ${ }^{19}$.

Acredita-se que os imigrantes japoneses e principalmente escravos africanos foram os responsáveis pela disseminação do HTLV no Brasil, já que ambas as regiões sempre foram conhecidas por seu endemismo. E esta pode ser a explicação para os altos índices de prevalência do vírus em cidades brasileiras que, na época colonial, tinham movimentado comércio negreiro, a exemplo a cidade de Salvador (BA) e São Luís $(\mathrm{MA})^{27,24}$.

Em países como o Brasil, Japão, Caribe, África do Sul, Nigéria e República do Congo, o HTLV é endêmico. Atualmente estima-se que cerca de 20 milhões de pessoas estejam infectadas pelo HTLV-I no mundo. No Brasil, estudos mostram sua presença em todo 0 território nacional (com prevalência diferente em cada região) e que o país possui o maior número de infectados, com estimativa de 2,5 milhões. Os maiores índices são observados em populações indígenas e estados com alto número de remanescentes de escravos africanos e imigrantes japoneses. Estudo realizado com o intuito de avaliar a prevalência do HTLV em doadores de sangue das 27 capitais brasileiras, concluiu que a heterogeneidade entre as regiões é considerável. Os dados obtidos apresentaram divergência acentuada de 0,4/1.000 em 
Florianópolis (SC) a uma taxa 25 vezes maior $(10,0 / 1.000)$ em São Luís (MA) ${ }^{9,8,4}$.

Triagem e confirmação são as etapas que devem ser seguidas para o diagnóstico do HTLV. Os testes de triagem são os mais utilizados para 0 diagnóstico laboratorial e envolvem técnicas de imunoensaio e aglutinação. Os testes de imunoensaio, como ELISA, por exemplo, são responsáveis pelo rastreio de ambos os tipos de HTLV, ao passo que os testes de aglutinação rastreiam apenas o tipo I (HTLV-I). Poro Brasil ser um país endêmico para ambos os tipos do vírus (HTLV-I e II), os testes de imunoensaio são os mais utilizados. Western Blot, Imunofluorescência indireta (IFA) e radioimunoprecipitação (RIPA) são testes utilizados para confirmação e discriminação entre os tipos virais $\left(\right.$ HTLV-I ou HTLV-II) ${ }^{13}$.

ELISA: teste de triagem que detecta anticorpos produzidos pelo corpo do hospedeiro contra o HTLV. Os antígenos mais utilizados são as proteínas recombinantes advindas dos genes virais env e gag, e aqueles encontrados no lisado viral do HTLV-I e HTLV-II, 4.

Western Blot: teste de caráter confirmatório também capaz de discernir o tipo de HTLV envolvido na infecção (HTLV-I ou HTLV-II). Atua por meio da incorporação de proteínas, como: gpR46-1 e gpR462 (proteínas presentes no envelope), GD21 (proteína recombinante) e proteínas transmembranares ${ }^{3,4}$.

PCR: diagnóstico qualitativo e quantitativo: na rotina laboratorial alguns resultados obtidos a partir de testes confirmatórios iniciais podem apresentar-se de forma indeterminada, ambígua ou imprecisa. Em situações como esta devem ser feitos testes confirmatórios de análise molecular qualitativa e quantitativa de reação em cadeia de polimerase (PCR). Suas principais vantagens são a sua alta sensibilidade, especificidade e o fato de não depender da produção de anticorpos, já que investiga diretamente o material genético do vírus $^{3,4}$.

O HTLV não tem cura e o tratamento para portadores do HTLV e doenças associadas, é um assunto desafiador. Os estudos mais aprofundados que trouxeram as primeiras respostas às lacunas existentes acerca do ciclo biológico do HTLV são relativamente recentes, e ainda precisam ser ampliados. Pacientes portadores de doenças associadas ao HTLV em geral tem quadro clínico de avanço lento ou até assintomático. Quando os primeiros sintomas da infecção começam a se manifestar, normalmente o paciente já tem idade avançada e, nos poucos casos em que este consegue um diagnóstico preciso a tempo de retardar o avanço da infecção, a profilaxia já é ineficiente e os métodos de tratamento tem apenas - papel de melhorar ao máximo possível a qualidade de vida do paciente ${ }^{15}$.

\section{Material e Método}

A construção dos dados pertinentes a esta revisão foi feita baseada em ampla extração de informações a partir de artigos científicos publicados nos principais periódicos científicos nacionais e 
internacionais, a saber: Scielo, PubMed (US National Library of Medicine /National Institutes of Health) e LILACS.

Para a busca dos artigos foram utilizadas as seguintes palavras chave: "HTLV", "HTLV-I Infections", "HTLV-II", "Prevalence of HTLV" e "HTLV no Brasil". Um total de 40 artigos foi selecionado levando-se em consideração o ano de publicação mais recente e enquadramento na linha de pesquisa. Após avaliação completa por meio de leitura crítica dos seus respectivos conteúdos, 11 artigos foram excluídos por terem dados irrelevantes ou já ultrapassados por publicações mais recentes, ano de publicação e enquadramento na linha de pesquisa. Finalizando-se a pesquisa com um total de 29 fontes bibliográficas.

\section{Resultados}

O HTLV caracteriza-se como vírus de fácil transmissão, assintomático e associado a graves doenças de caráter degenerativo. A desinformação e dificuldades enfrentadas por pacientes HTLVpositivos,e até por parte de profissionais da área da saúde durante a fase de diagnóstico e tratamento,reflete 0 desmazelo acerca da contenção da transmissão, políticas de divulgação do HTLV / doenças associadas e incentivo a pesquisa, principalmente por parte do ministério da Saúde e órgãos de vigilância epidemiológica.

\section{Discussão}

No Brasil a triagem do HTLV é negligenciada, com ineficiência dos serviços de diagnóstico, atendimento e, principalmente, acompanhamento dos pacientes. Em cartilha disponibilizada pelo Governo Federal, através do Ministério da Saúde, o órgão admite a problemática, ao afirmar categoricamente que: "Não há proposta de triagem de HTLV no atendimento primário às DST's devido às restrições de acesso a diagnóstico e tratamento" ${ }^{1}$. No país, apenas doadores de sangue fazem testes de triagem compulsórios, o que dificulta sua identificação, tratamento e contenção da sua transmissão ${ }^{17}$.

O tratamento das doenças decorrentes da infecção pelo vírus HTLV vai muito além das intervenções médico-farmacológicas. A avaliação dos aspectos que envolvem a qualidade de vida do paciente, por exemplo, é vital para assegurar que este tenha as doenças que the causam desconfortos, principalmente físicos e sociais, devidamente atendidas. De acordo com Delazeri et $a^{5}$ :

"A qualidade de vida ligada à saúde pode ser definida como o valor atribuído à vida, pelas deteriorações funcionais; as percepções e condições sociais que são induzidas pela doença, agravos, tratamentos e a organização política e econômica do sistema assistencial".

A falta de conhecimento técnico-científico é recorrente por parte dos profissionais da área da saúde, e esta é apenas uma das barreiras que os portadores do HTLV precisam enfrentar. A longa espera por um diagnóstico (que às vezes é dado de forma errônea), a nítida percepção de perda de funções, a agonia por conta dos desconfortos físicos e o preconceito 
por parte daqueles que confundem o vírus HTLV com o vírus HIV, tornam a busca por um tratamento que, de fato gere resultados, quase inalcançável. Situações de estresse emocional e incertezas acerca do tempo de vida podem levar o paciente portador do HTLV ao desenvolvimento de depressão.

O aconselhamento é uma prática que deve ser incentivada e fazer parte da rotina de tratamento dos portadores do HTLV. No entanto, como o vírus é assintomático, tem poucas informações disponíveis em trabalhos científicos e pouco se debate publicamente sobre ele, esta tarefa se torna comprometida e, muitas vezes abandonada. Afinal, para que o correto aconselhamento acerca do HTLV seja feito é necessário que o profissional da área da saúde possua conhecimento científico compatível com a magnitude desta tarefa.

\section{Conclusão}

O melhor tratamento para o HTLV é a prevenção! É preciso que esforços sejam tomados para garantir que, a exemplo do que foi feito no Japão, haja o devido controle das formas de propagação da doença, seja por vias tidas como habituais (via sexual, materiais perfuro-cortantes, por exemplo), seja por via sanguínea decorrente de triagem ineficiente em hemocentros, seja por transmissão vertical (de mãe para filho).

Enquanto ações nesse sentido não são tomadas, faz-se necessário que, no mínimo, o correto prognóstico seja efetuado, para que o portador do HTLV possa ser diagnosticado e tratado o quanto antes a fim de evitar ou retardar o aparecimento de doenças associadas, e a perda das capacidades físicas, sociais e emocionais de cada individuo.

\section{Referências}

1. Ministério da Saúde (Brasil). Secretaria de Vigilância em Saúde. Programa Nacional de DST e Aids. Manual de controle das doenças sexualmente transmissíveis. $4 a$ ed. Brasília: Ministério da Saúde; 2006.

2. Andrade RG. Análise da expressão de tax e $h b z$ e de genes celulares relacionados com a resposta imune inata e adaptativa em portadores assintomáticos e pacientes com HAM/TSP com baixa ou alta carga proviral do HTLV-1 (Human Tlymphotropic vírus 1). [Dissertação de Mestrado]. Belo Horizonte: Universidade Federal de Minas Gerais, Belo Horizonte, 2012.

3. Araújo THA. Desenvolvimento de um banco de dados (HTLV-1 molecular Epidemiology Database) para data-mining e data management de sequências do HTLV-1. [Dissertação de Mestrado]. Salvador: Fundação Oswaldo Cruz, Centro de pesquisas Gonçalo Moniz, Curso de Pós-Graduação em Biotecnologia em Saúde e Medicina Investigativa, 2012.

4. Barmpas DBS, Monteiro DLM, Taquette SR,Trajano AJB, Raupp RM,Miranda FRD et al.Infecção pelo HTLV-1/2 em gestantes brasileiras. Revista HUPE, Rio de Janeiro, $2014 ; 13$ (3):80-87 / doi: 10.12957/rhupe.2014.12132 / v.13, n. 3, jul/set 2014. 
5. Delazeri LM, Santos LR, Mendes SMD, Baptista AF, Sá KN, Castro BG.Impacto dos Aspectos Sociodemográficos e Clínicos na Qualidade de Vida de Portadores de HTLV-I com HAM/TSP. Revista Pesquisa em Fisioterapia, 2(1): Jan/2012.

6. Drezett J, Blakea MT, Lirab KSF, Pimentel RM, Adamia F, Bessab MMM. Doenças sexualmente transmissíveis em mulheres que Sofrem crimes sexuais.Sociedade Brasileira de Reprodução Humana. Elsevier Editora Ltda, Reprodução \& climatério, 2 7(3):109-116, 2013.

7. Ferreira AW, Ávila SL.Diagnóstico laboratorial: avaliação de métodos de diagnóstico das principais doenças infecciosas e parasitárias e autoimunes, correlação clinicolaboratorial. 2.ed. Rio de Janeiro: Guanabara Koogan; 2001.

8. Gessain A, Cassar $O$. Epidemiological aspects and world distribution of HTLV-1 infection. Frontiers in Microbiology, November, Volume 3, Article 388, DOI: $\quad 10.3389 / f m i c b .2012 .00388$, 2012.

9. Gomes FVBAF, Junior JE. HTLV II em doadores de sangue na Hemorrede do Ceará - HEMOCE. Revista da Assoc. Médica Brasileira, 57(3):315-318, 2011.

10. Kozlowskl AG, Carneiro MAS, Matos MAD, Filho SAT, Otsuki K, Vicente ACP et al. Prevalence and genetic characterization of HTLV-1 and 2 dual infections in patients with pulmonary tuberculosis in CentralWest Brazil. Inst. Oswaldo Cruz, Rio de Janeiro, Vol. 109(1): 118-121, February 2014.

11. Lima MVA. Avaliação fenotípica e funcional dos linfócitos $T$ citotóxicos de indivíduos infectados pelo HTLV1 com diagnóstico de HAM/TSP. 118 f. il. [Dissertação de Mestrado]. Salvador: Fundação Oswaldo Cruz. Centro de Pesquisas Gonçalo Moniz, Salvador, 2014.

12. Martins FM, Rezende NPM, Magalhães MHCG, Ortega KL.Conhecendo o HTLV e suas implicações no atendimento odontológico. RGO - Revista Gaúcha Odontol. Porto Alegre, v.59, n.2, p.293-297, abr./jun., 2011.

13. Martins ML, Romanelli LCF, Miranda AB, Ribeiro MA, Brito ILA, Fonseca FG et al.Infecção pelo HTLV-1/2: estratégias de diagnóstico e estudo da evolução clínica e coinfecções associadas. Gerais: Revista de Saúde Pública do SUS/MG Volume 1 - N 1, 2013.

14. Miranda ACAM.Estudo molecular de proteínas estruturais (gp21 e gp46) e regulatórias (HBZ) do HTLV-1 em indivíduos com diferentes perfis clínicos. 92 f. il. [Tese de Doutorado].Salvador: Fundação Oswaldo Cruz, Instituto de Pesquisas Gonçalo Moniz, 2012.

15. Nascimento LR, Moreira VS, Cunha MS, Mattos PDM, Cavalcante FS, Helena AAS et al. Mielopatia Sinalizando o Diagnóstico Tardio da Infecção por HTLV: Um Relato de Caso. DST - J. bras. Doenças Sexualmente Transmissíveis, 24(4):267-271, 2012.

16. Neto IF, Mendonça RP, Nascimento CA, Mendes SMD, Sá KN.Fortalecimento muscular em pacientes com HTLV-I e sua Influência no desempenho funcional: um estudo piloto. Revista Pesquisa em Fisioterapia, Salvador, dez. 2(2): 143-155, 2012. 
17. Oliveira EH, Silva FL, Silva ML.Perfil epidemiológico dos doadores de sangue infectados pelo vírus HTLV I/II, no Estado do Piauí. ISSN 2317 5079 / R. Interd. v. 8, n. 1, p. 149156, jan. fev. mar. 2015.

18. Ozawa PMM, Reis DAS, Kurauti MA, Simões TMG, Oda JMM, Carneiro NK.Vírus linfotrópico de células $\mathrm{T}$ humano tipo 1 (HTLV-1): implicações em doenças autoimunes. Ciências Biológicas e da Saúde, Londrina, v. 33, n. 1, p. 83-96, jan./jun, DOI: 10.5433/16790367.2012v33n1p83, 2012.

19. Paiva A, Casseb J. Origin and prevalence of human T-lymphotropic virus type 1 (HTLV-1) and type 2 (HTLV-2) among indigenous populations in the Americas. Rev. Inst. Med. Trop. São Paulo, 57(1): 113, 2015.

20. Pinto MT, Rodrigues ES, Malta TM, Azevedo R, Takayanagui OM, Valente VB et al.HTLV-1/2 seroprevalence and coinfection rate in brazilian first-time blood donors: an 11-year follow-up. Rev. Inst. Med. Trop. Sao Paulo, 54(3):123129, May-June, 2012.

21. Proietti ABFC, Ribas JGR, CatalanSoares BC, Martins ML,Brito-Melo GEA, Filho OAM. Infecção e doença pelos vírus linfotrópicos humanos de células $T$ (HTLV-I/II) no Brasil. Revista da Sociedade Brasileira de Medicina Tropical, 35(5): 499-508, set-out, 2002.

22. Santos E O. Caracterização molecular do Vírus Linfotrópico de Células $\mathrm{T}$ de Humano (HTLV) em pacientes com Paraparesia Espástica Tropical/ Mielopatia (PET/MAH), portadores e gestantes em Alagoas.[Tese de Doutorado]. Recife: Universidade Federal de
Pernambuco, Centro de Ciências da Saúde, Programa de pós-graduação em Medicina Tropical, 2013.

23. Santos SB, Oliveira $P$, Luna $T$, Souza A, Nascimento M, Siqueira I. Immunological and viral features in patients with overactive bladder associated with human $\mathrm{T}$-cell lymphotropic virus type 1 infection. Journal of medical virology. Dec;84(11):1809-17, 2012.

24. Santos RFS. Prevalência do Vírus Linfotrófico de Células $T$ Humanas tipo 1 (HTLV-1) nos pacientes em hemodiálise de manutenção em Salvador. [Dissertação Mestrado].Salvador: Universidade Federal da Bahia, 2013.

25. Santos V S, Rivemales MCC. Facilidades e dificuldades encontradas na realização do Aconselhamento às pessoas que vivem com HTLV. DOI: 10.4025/cienccuidsaude.v11i3.2026 2 / Cienc. Cuid. Saúde, Jul/Set; 11(3):542-548, 2012.

26. Sousa AS.Diminuição da resposta imune ao Toxóide tetânico em indivíduos Infectados pelo HTLV-1. [Tese de Doutorado]. Salvador: Universidade Federal da Bahia, 2012.

27. Souza VG, Martins ML, Proietti ABFC, Januário JN, Ladeira RVP, Silva CMS. High prevalence of HTLV-1 and 2 viruses in pregnant women in São Luís, State of Maranhão, Brazil. Revista da Sociedade Brasileira de Medicina Tropical 45(2):159-162, mar-abr, 2012.

28. Teixeira IB, Boa-Sorte N, Kruschewsky R, Araújo T, Grassi MF, Castro BG. Incidence of tropical spastic parapesis/ HTLV-1 associated myelopathy/ (TSP/HAM) 
in patients followed in a Reference center in Salvador, Brazil. 17th International Conference on Human Retroviruses: HTLV and Related Viruses Trois Ilets, Martinique. 1821 June 2015.

29. Viana GMC, Silva MACN, Souza VL, Lopes NBS, Nascimento MDSB. Case Report Endemic transmission of HTLV-2 in blood donors from São Luís do Maranhão, northeastern Brazil: report of two asymptomatic individuals. Brazilian Journal of Hematology and Hemotherapy, rev bras hematolhemoter. 3 7(2):130131, 2015. 